\title{
A Combination of Hypoxia and Lipopolysaccharide Activates Tristetraprolin to Destabilize Proinflammatory mRNAs such as Tumor Necrosis Factor- $\alpha$
}

\author{
Christian Werno, Tobias Schmid, \\ Steffen E. Schnitzer, Kathrin Peters, \\ Larissa Milke, and Bernhard Brüne \\ From the Faculty of Medicine, Institute of Biochemistry I/ZAFES, \\ Goethe-University Frankfurt, Frankfurt, Germany
}

Inflammation is often accompanied by hypoxia because of the high oxygen consumption of invading bacteria and immune cells. During resolution of inflammation, the formation of inflammatory mediators such as tumor necrosis factor- $\alpha$ (TNF- $\alpha$ ), which is produced by macrophages, needs to be terminated. We show in RAW264.7 macrophages that TNF- $\alpha$ mRNA as well as intracellular and secreted TNF- $\alpha$ protein levels are reduced after prolonged incubations with lipopolysaccharide (LPS) under hypoxic conditions. The decrease in TNF- $\alpha$ was mediated by destabilization of TNF- $\alpha$ mRNA via a 3 -untranslated region-dependent mechanism. Specifically, the RNA-binding protein tristetraprolin (TTP) increased at mRNA and protein levels after 16-hour incubations with LPS under hypoxia. Interestingly, TTP accumulated in a dephosphorylated and active form, and this accumulation was attributable to reduced $\mathbf{p} 38$ mitogen-activated protein $\mathbf{k i}$ nase activity under these conditions. Knockdown of TTP by small interfering RNA abolished destabilization of TNF- $\alpha$ mRNA. Prolonged incubations with LPS under hypoxia also reduced mRNA amounts and stability of other proinflammatory mediators such as macrophage inflammatory protein- 2 , interleukin-6, and granulocyte macrophage colony-stimulating factor. Therefore, we propose that hypoxia plays a key role during resolution of inflammation by activating posttranscriptional, TTP-dependent regulatory mechanisms. (Am J Pathol 2010, 177:1104-1112; DOI: 10.2353/ajpath.2010.091212)

Inflammation is a first line of defense against pathogens facilitated by immune cells. Macrophages represent an important constituent of the infiltrate; they contribute to the initially destructive milieu by secreting proinflammatory mediators such as tumor necrosis factor- $\alpha$ (TNF- $\alpha$ ). Substantial immune cell activation at inflammatory sites increases oxygen consumption, resulting in hypoxic areas. Oxygen levels less than 1\% have been reported for various disease scenarios, whereas the oxygen tension is between 2.5 and $9 \%$ oxygen under healthy conditions. ${ }^{1}$ Current studies have been mainly focused on the impact of hypoxia on lipopolysaccharide (LPS)-induced TNF- $\alpha$ production in the early response to pathogens, ${ }^{2-5}$ however, mechanisms contributing to the resolution of inflammation under hypoxic conditions remain elusive.

Currently, there are conflicting data concerning the regulation of TNF- $\alpha$ in macrophages in response to combined exposure to hypoxia and LPS. It was shown that hypoxia acts synergistically with LPS to transcriptionally regulate TNF- $\alpha$ via activation of nuclear factor $-\kappa \mathrm{B}^{2,4}$ and/or hypoxia-inducible factor-1., ${ }^{3,6}$ In general, hypoxia has either been shown not to affect or even to increase LPS-dependent TNF- $\alpha$ mRNA expression during incubations lasting up to 6 hours h $^{2,5,7}$ as well as protein secretion during up to 18-hour incubations. ${ }^{2,3,7}$ Recently, Lahat et $\mathrm{al}^{8}$ proposed that long-term (24 hours) exposure to hypoxia/LPS reduced TNF- $\alpha$ protein with mRNA levels being unchanged, which was attributed to increased lysosomal degradation of the TNF- $\alpha$ precursor protein, suggesting a mechanism for the negative regulation of TNF- $\alpha$.

Supported by grants from the Deutsche Forschungsgemeinschaft (BR999, ECCPS and GRK757 (C.W.)) and LOEWE Schwerpunkt Onkogene Signaltransduktion Frankfurt (OSF) funded by the Hessian Ministry of Higher Education, Research and Arts.

C.W. and T.S. contributed equally to this work.

Accepted for publication May 20, 2010.

None of the authors disclose any relevant financial relationships.

Supplemental material for this article can be found on http://ajp. amjpathol.org.

Address reprint requests to Dr. Bernhard Brüne, Goethe-University Frankfurt, Faculty of Medicine, Institute of Biochemistry I/ZAFES, Pathobiochemistry, Theodor-Stern-Kai 7, Bldg. 74, 60590 Frankfurt, Germany. E-mail: bruene@pathobiochemie1.de. 
TNF- $\alpha$ was also shown to be regulated via stability of its mRNA. Specifically, the mRNA-binding and -destabilizing protein tristetraprolin (TTP) binds to a conserved adenosine/uridine-rich element (ARE) within the $3^{\prime}$-untranslated region ( $3^{\prime}-$ UTR) of TNF- $\alpha$ mRNA, provoking its rapid degradation. ${ }^{9}$ TTP was also reported to regulate mRNA stability of various other inflammatory mediators such as macrophage inflammatory protein-2 (MIP-2), interleukin (IL)-2, IL-6, interferon- $\gamma$, and granulocyte macrophage colony-stimulating factor (GM-CSF). ${ }^{10-14}$ The availability of TTP is regulated via transcriptional mechanisms and via proteasomal degradation. Importantly, TTP in its active, dephosphorylated state binds to target mRNAs to facilitate their degradation. During this process TTP protein seems to be co-degraded. ${ }^{15-17}$ Phosphorylation of TTP at serines 52 and 178 by p38-mitogen-activated protein kinase (MAPK)/mitogen-activated protein kinase-activated protein kinase-2 causes inactivation and concomitant accumulation of the protein. Accumulation is due to binding of the chaperone 14-3-3 to phosphorylated TTP, which prevents degradation of the latter. ${ }^{18,19}$

Here, we provide evidence that long-term hypoxia decreases LPS-dependent TNF- $\alpha$ production by reducing TNF- $\alpha$ mRNA stability. Mechanistically, prolonged exposure to hypoxia and LPS reduces p38-MAPK activity, attenuates phosphorylation of TTP, and thereby increases the activity of TTP, which destabilizes TNF- $\alpha$ mRNA. Interestingly, our data suggest that under these conditions TTP remains stable in a dephosphorylated form. Considering mRNA destabilization of additional proinflammatory mediators under these conditions, TTP seems to be a key factor during resolution of inflammation in macrophages under prolonged hypoxic conditions.

\section{Materials and Methods}

\section{Materials}

Medium and supplements were purchased from PAA (Linz, Austria). Fetal calf serum was from Biochrom (Berlin, Germany). Triton X-100, LPS (from Escherichia coli, serotype 0127:B8), and 4,6-diamidino-2-phenylindole were from Sigma-Aldrich (Schnelldorf, Germany). Nitrocellulose membrane, the ECL detection system, anti-actin antibody (Ab) and horseradish peroxidase-labeled anti-mouse or anti-rabbit secondary Abs were supplied by GE Biosciences (Freiburg, Germany). Anti-p38, anti-phospho-p38 and antiTNF- $\alpha$ Abs were purchased from Cell Signaling (Frankfurt, Germany). Cy3-labeled anti-rat secondary Ab was from Dianova (Hamburg, Germany). Rabbit antiserum against murine TTP was kindly provided by Dr. A. R. Clark (London, UK). ${ }^{20}$ Anti-phospho-TTP $A b$ and luciferase reporter plasmids pMT2-luc-control and pMT2-luc-TNF-3'-UTR were kindly provided by Dr. G. Stoecklin (Heidelberg, Germany). ${ }^{18,21}$

\section{Cell Culture}

The mouse monocyte/macrophage cell line RAW264.7 was cultured in RPMI 1640 supplemented with $100 \mathrm{U} / \mathrm{ml}$ penicillin, $100 \mu \mathrm{g} / \mathrm{ml}$ streptomycin, and 10\% heat-inactivated fetal calf serum. Cells were kept at $37^{\circ} \mathrm{C}$ in a humidified atmosphere with $5 \% \mathrm{CO}_{2}$. For hypoxic exposures, cells were placed in an Invivo 2400 Hypoxia Working Station (Ruskin Technology, Leeds, UK) at $1 \% \mathrm{O}_{2}$, $94 \% \mathrm{~N}_{2}$, and $5 \% \mathrm{CO}_{2}$.

\section{Western Analysis}

One day before experiments, $5 \times 10^{5}$ RAW264.7 cells were seeded in 6-cm dishes. On the following day medium was changed, and cells were treated as indicated. Cell extracts were prepared in $100 \mu$ l of lysis buffer (50 $\mathrm{mmol} / \mathrm{L}$ Tris/ $\mathrm{HCl}, 150 \mathrm{mmol} / \mathrm{L} \mathrm{NaCl}, 5 \mathrm{mmol} / \mathrm{L}$ EDTA, $0.5 \%$ Nonidet-40, and protease inhibitor cocktail, pH 8.0) by sonication. The protein content was determined using a BCA protein assay kit (Bio-Rad, Munich, Germany). Subsequently, $100 \mu \mathrm{g}$ of protein was resolved on 10\% SDSpolyacrylamide gels and blotted onto nitrocellulose membranes. Proteins were detected using specific antibodies and appropriate secondary antibodies and visualized by enhanced chemiluminescence. Quantification of Western blots was done using Aida Image Software (Raytest Isotopenmessgeraete, Straubenhardt, Germany).

\section{Quantitative Real-Time RT-PCR}

One day before experiments, $5 \times 10^{5}$ RAW264.7 cells were seeded in 6-cm dishes. On the following day medium was changed, and cells were treated as indicated. Total RNA was isolated using a pegGOLD RNAPure kit (Peglab, Erlangen, Germany). Reverse transcription was completed with an iScript cDNA Synthesis kit (Bio-Rad). The following primer pairs were used for quantitative real-time PCR: TNF- $\alpha$, forward 5'-CCATTCCTGAGTTCTGCAAAGG-3' and reverse 5'-AGGTAGGAAGGCCTGAGATCTTATC-3'; ribosomal protein $\mathrm{S} 16$ forward 5'-AGATGATCGAGCCGCGC-3' and reverse 5'-GCTACCAGGGCCTTTGAGATGGA-3'; interleukin-6 forward 5'-GAACAACGATGATGCACTTGC-3' and reverse 5'-TCTCTGAAGGACTCTGGCTTTG-3'; and GM-CSF forward 5'-ACTCCGGAAACGGACTGTGAAACA-3' and reverse 5'-TGTGCCACATCTCTTGGTCCCTTT-3'. TTP and MIP-2 primer pairs were purchased from Qiagen (Hamburg, Germany).

\section{Transfection and Reporter Analysis}

The pMT2-luc-TNF-3'-UTR reporter construct containing the $3^{\prime}$-UTR of murine TNF- $\alpha$ behind the luciferase gene was used to assess $3^{\prime}$-UTR-dependent changes in TNF- $\alpha$ mRNA stability. The pMT2-luc-control was used as a reference. One day before experiments, $1 \times 10^{5}$ RAW264.7 cells were seeded in 6-well plates. Cells were transfected with $2 \mu \mathrm{g}$ of individual reporter plasmids using jetPEItransfection reagent according to the manufacturer's protocol (Biomol, Hamburg, Germany). After 4 hours medium was changed, and cells were treated as indicated for 16 hours. Cells were lysed, and luciferase activity was measured. Relative luciferase activity of treated cells was 
calculated by normalizing values to those of control plasmid transfected cells.

Small interfering (si) RNAs against murine TTP (Dharmacon, Schwerte, Germany) and nontargeting siRNA (Qiagen, Hamburg, Germany) were transfected using the AMAXA nucleofection system according to the manufacturer's protocol (Amaxa, Cologne, Germany). After 4 hours the medium was changed, and cells were incubated for 24 hours and then treated as indicated.

\section{Mouse Inflammation Cytometric Bead Array}

One day before experiments, $5 \times 10^{5}$ RAW264.7 cells were seeded in $6-\mathrm{cm}$ dishes. On the following day medium was changed, and cells were treated as indicated. Supernatants were collected, and TNF- $\alpha$ measurements were performed using the BD Cytometric Bead Array Mouse TNF Flex Set according to the manufacturer's protocol. Samples were analyzed with the FACSCanto flow cytometer and processed with BD Biosciences FCAP software (BD Biosciences, Heidelberg, Germany).

\section{Immunocytochemistry}

One day before experiments, $1 \times 10^{5}$ RAW cells were seeded on coverslips. On the following day medium was changed, and cells were treated as indicated. After being washed with PBS, cells were fixed with $4 \%$ paraformaldehyde. Cells were then treated for 20 minutes with $2 \%$ Triton X-100-PBS followed by blockade of unspecific binding for 1 hour at room temperature with $10 \%$ fetal calf serum in $0.01 \%$ Triton X-100-PBS. The anti-TNF- $\alpha$ Ab was incubated overnight at $4^{\circ} \mathrm{C}$. Cells were then washed and incubated with anti-rat-FITC Ab for 1 hour at room temperature. 4,6-Diamidino-2-phenylindole was added for the last 30 minutes to stain nuclei. Specimens were mounted on glass slides, and fluorescence was analyzed using an Axiovert 200M microscope (Zeiss, Goettingen, Germany).

\section{Statistical Analysis}

Each experiment was performed at least three times. Representative blots are shown. Data are presented as mean values \pm SEM. Statistical analysis was performed using Student's t-test (Microcal Origin, version 6.0). Unless indicated otherwise, differences marked with asterisks were considered to be significant at $P \leq 0.05$.

\section{Results}

\section{Prolonged Treatment with Hypoxia/LPS Reduced TNF- $\alpha$ mRNA and Protein Amounts}

Initially, TNF- $\alpha$ mRNA levels were determined after 4,8 , and 16 hours under normoxic and hypoxic (1\% oxygen) conditions with or without the addition of LPS in RAW264.7 macrophages. LPS treatment induced TNF- $\alpha$
mRNA at 4 and 8 hours similarly under normoxia and hypoxia (Figure 1A). In contrast, LPS-induced TNF- $\alpha$ mRNA accumulation at 16 hours was significantly reduced from $24.4 \pm 3.79$-fold induction under normoxia to

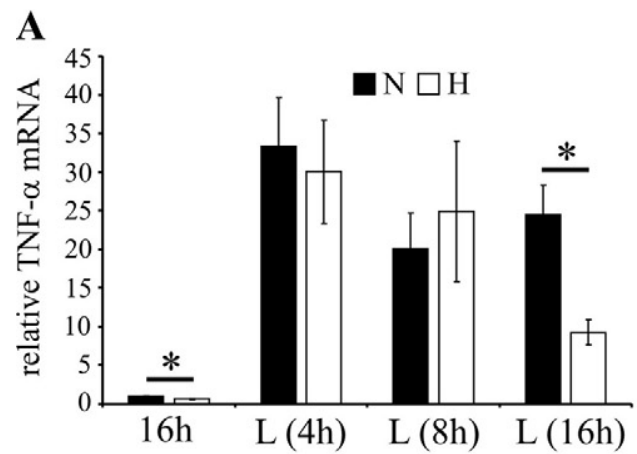

B
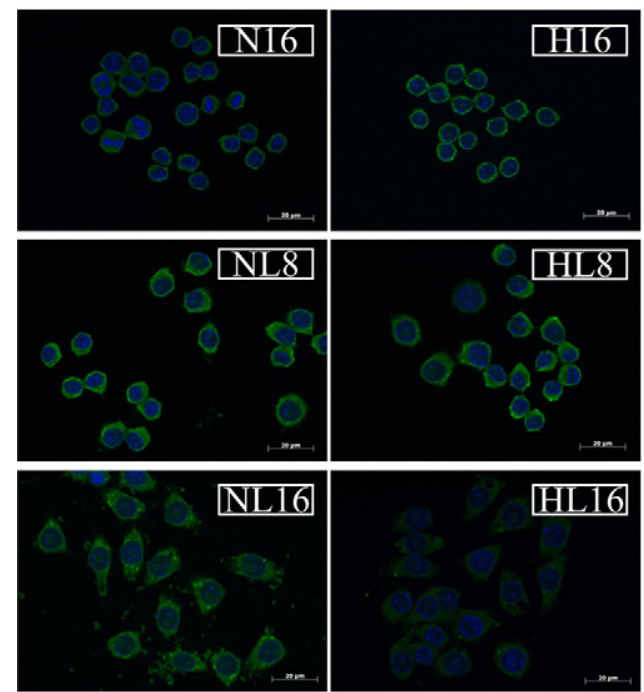

C

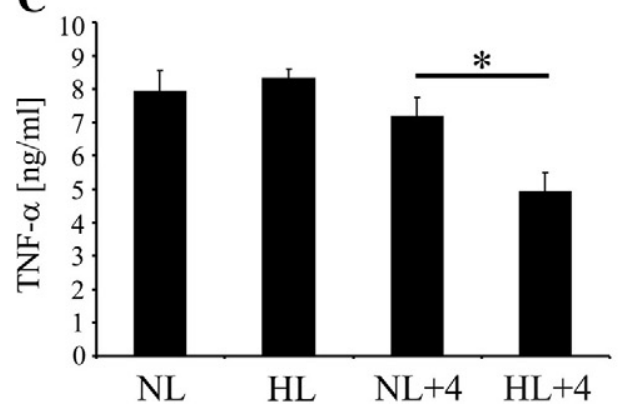

Figure 1. Hypoxia/LPS reduces TNF- $\alpha$ mRNA and protein amount. A RAW264.7 cells were treated for the indicated times under normoxia (N, black bar) or hypoxia ( $\mathrm{H}$, white bar) with or without LPS $(1 \mu \mathrm{g} / \mathrm{ml})(\mathrm{L})$. TNF- $\alpha$ mRNA levels were normalized to ribosomal protein mRNA and calculated relative to normoxic levels as determined by quantitative real-time RT-PCR. B: RAW264.7 cells were treated for 8 or 16 hours under normoxia (N16) hypoxia (H16), normoxia/LPS (NL8, NL16), or hypoxia/LPS (HL8, HL16). Intracellular TNF- $\alpha$ protein (green) was visualized by immunocytochemistry. 4,6-Diamidino-2-phenylindole staining (blue) was used to stain nuclei. Results are representative of at least three independent experiments. An objective lens A-Fluor-40x/1.30 was used. C: RAW264.7 cells were treated for 16 hours with LPS under normoxia (NL) or hypoxia (HL). In addition, medium was changed after 16 hours, and incubations were continued for four hours with LPS under normoxia $(\mathrm{NL}+4)$ or hypoxia $(\mathrm{HL}+4)$. Supernatants were collected, and TNF- $\alpha$ was determined by cytometric bead array analysis. Data are the means $\pm \operatorname{SEM}(n=\geq 3)$. Significant changes ${ }^{*} P<0.05$. 
$9.2 \pm 1.62$-fold induction under hypoxia (Figure 1A). A 16-hour-long incubation under hypoxia without LPS attenuated TNF- $\alpha$ mRNA to $0.64 \pm 0.07$-fold compared with normoxia. Because TNF- $\alpha$ is only expressed at significant levels under LPS-induced conditions, we further investigated TNF- $\alpha$ mRNA regulation under hypoxia/LPS. To verify mRNA reduction by hypoxia/LPS, we used primary mouse macrophages. In primary macrophages, we recapitulated a significant TNF- $\alpha$ mRNA reduction after 16-hour incubations under hypoxia/LPS compared with normoxia/LPS (supplemental Figure S1, see http://ajp.amjpathol.org). To determine whether the mRNA decrease also affects TNF- $\alpha$ protein expression, intracellular TNF- $\alpha$ precursor protein levels were analyzed. Although the exposure to LPS for 8 hours increased TNF- $\alpha$ precursor protein levels similarly under normoxic and hypoxic conditions, only incubations for 16 hours under normoxia/LPS increased TNF- $\alpha$ precursor protein, whereas incubations under hypoxia/LPS attenuated this increase to levels of non-LPS conditions (Figure 1B). We then determined whether the decrease in intracellular TNF- $\alpha$ precursor reduced the amount of released, bioactive protein. Because differences in TNF- $\alpha$ mRNA between normoxia/LPS and hypoxia/LPS occurred after 16 hours only (Figure $1 \mathrm{~A}$ ), it was not surprising that equal amounts of TNF- $\alpha$ protein were secreted from macrophages stimulated with normoxia/LPS or hypoxia/LPS for 16 hours (Figure 1C). Therefore, we reasoned that a reduction in TNF- $\alpha$ mRNA and intracellular precursor protein observed after prolonged incubations under hypoxia/ LPS should attenuate de novo secretion of bioactive TNF- $\alpha$. To test this, we preincubated macrophages for 16 hours, changed the medium, and continued incubations for 4 hours. In this experimental setup the amount of TNF- $\alpha$ protein released under hypoxia/LPS (4.92 \pm 0.57 $\mathrm{ng} / \mathrm{ml}$ ) was significantly reduced compared with that released under normoxia/LPS (7.18 $\pm 0.56 \mathrm{ng} / \mathrm{ml}$ ) (Figure 1C). Apparently, prolonged incubations with LPS under hypoxic conditions decreased TNF- $\alpha$ mRNA accumulation and diminished intracellular as well as secreted TNF- $\alpha$ protein levels compared with LPS treatments under normoxia.

\section{Hypoxia/LPS Destabilized TNF- $\alpha$ mRNA}

To investigate whether the decrease in TNF- $\alpha$ mRNA (Figure 1A) could be attributed to reduced transcriptional activity or to regulation of mRNA stability, we incubated cells for 4 or 16 hours with normoxia/LPS or hypoxia/LPS before blocking transcription by addition of actinomycin $\mathrm{D}(2.5 \mu \mathrm{g} / \mathrm{ml})$ for another 30 minutes. Preincubations with normoxia/LPS and hypoxia/LPS for 4 hours yielded comparable TNF- $\alpha$ mRNA stabilities $\left(t_{1 / 2}=25.8\right.$ and 28.5 minutes, respectively), which were in the same range as the stability determined after normoxia/LPS treatments lasting for 16 hours $\left(t_{1 / 2}=32.7\right.$ minutes) (Figure $\left.2 \mathrm{~A}\right)$. In contrast, TNF- $\alpha$ mRNA half-life under 16 hours of hypoxia/LPS was reduced to 15.7 minutes (Figure 2A). The $3^{\prime}-$ UTR of TNF- $\alpha$ contains several pentameric and
A

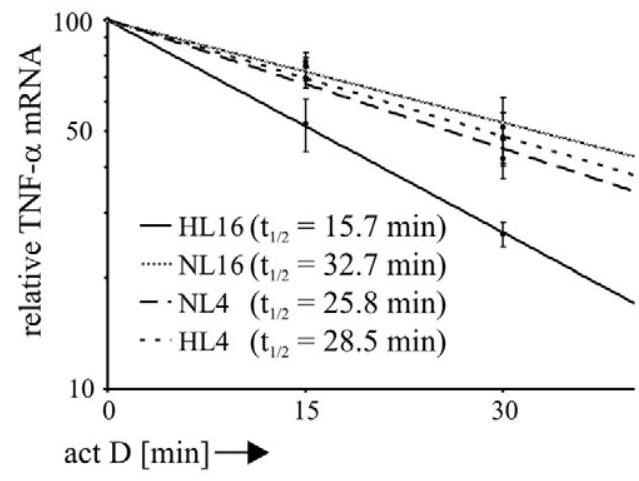

B $55^{\prime}$-CUCAGGCCUUCCUACCUUCAGACCUUUCCAG AUUCUUCCCUGAGGUGCAAUGCACAGCCUUCCUC ACAGAGCCAGCCCCCCUCUAUUUAUAUUUGCACU UAUUAUUUAUUAUUUAUUUAUUAUUUAUUUAUUU GCUUAUGAAUGUAUUUAUUUGGAAGGCCGGGGUG UCCUGGAGGACCCAGUGUGGGAAGCUGUCUUCAG ACAGACAUG $-3^{\prime}$

C

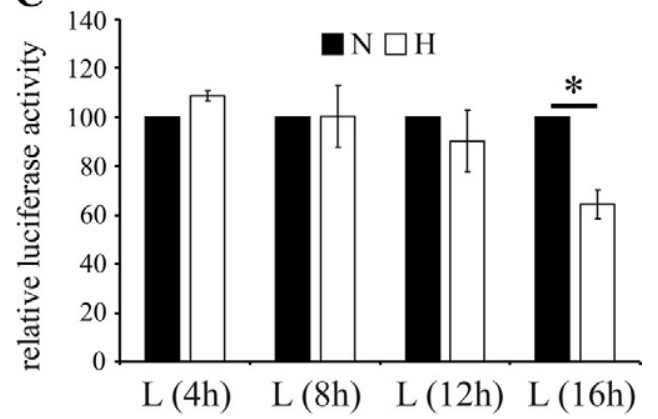

Figure 2. Hypoxia/LPS reduces $3^{\prime}$-UTR-dependent TNF- $\alpha$ mRNA stability A: RAW264.7 cells were exposed for 4 or 16 hours to normoxia/LPS $(1 \mu \mathrm{g} / \mathrm{ml})$ (NL4, NL16) or hypoxia/LPS (HL4, HL16). Subsequently, transcription was blocked by addition of actinomycin $\mathrm{D}(2.5 \mu \mathrm{g} / \mathrm{ml})$ for the times indicated. TNF- $\alpha$ and ribosomal protein mRNA were determined by quantitative realtime RT-PCR. The ratios of TNF- $\alpha$ to ribosomal protein mRNA after 16 hours of normoxia/LPS or hypoxia/LPS were set to 100. The half-life of the TNF- $\alpha$ mRNA was calculated by regression analyses. B: AU-rich region within the TNF- $\alpha$ 3'-UTR. Typical TTP binding sequences are highlighted. Pentameric AUUUA motifs are underlined, and nonameric UUAUUUAUU sequences are in bold. C: RAW264.7 cells were transfected with pMT2-luc-control or pMT2-luc-TNF-3'-UTR and stimulated for the times indicated with LPS (L) under normoxia $(\mathrm{N}$, black bar) or hypoxia $(\mathrm{H}$, white bar). The ratio of pMT2-luc-TNF-3'-UTR to pMT2-luc-control luciferase activity under normoxia was set as 100 for each time point. Data are the means $\pm \operatorname{SEM}(n=$ $\geq 3$ ). Significant changes ${ }^{*} P<0.05$

nonameric AU motifs, which are important for the AUbinding protein-dependent stability regulation of this transcript (Figure 2B). Therefore, we used the pMT2-Iuc-TNF$3^{\prime}$-UTR construct containing the $3^{\prime}$-UTR from murine TNF- $\alpha$ fused to a luciferase gene to evaluate whether destabilization could be attributed to a 3'-UTR-dependent mechanism. Figure $2 \mathrm{C}$ shows that the stability of the construct remained unchanged after 4, 8, or 12 hours of LPS treatment under either normoxia or hypoxia. However, long-term incubations for 16 hours under hypoxia/ LPS significantly reduced the stability to $64.54 \pm 5.9 \%$ of normoxia/LPS levels. Thus, long-term incubations under hypoxia/LPS destabilized TNF- $\alpha$ mRNA via a 3'-UTRdependent mechanism. 


\section{p38-MAPK-Determined Destabilization of $T N F-\alpha m R N A$}

p38-MAPK signaling plays a pivotal role in the posttranscriptional regulation of inflammatory genes by modulating the activity of ARE-binding proteins such as TTP. ${ }^{22}$ To address the impact of the p38-MAPK in our system, we inhibited p38-MAPK signaling using SB203580 (5 $\mu \mathrm{mol} / \mathrm{L}$ ) in macrophages exposed to normoxia/LPS to compare the TNF- $\alpha$ mRNA amount and stability with incubations under hypoxia/LPS. Figure 3A shows that the TNF- $\alpha$ mRNA induction under normoxia/LPS (24.4 \pm 3.79-fold) was significantly reduced to $8.3 \pm 1.04$-fold induction when p38-MAPK was inhibited. The reduction was similar to that observed under hypoxia/LPS alone (9.2 \pm 1.62 -fold).

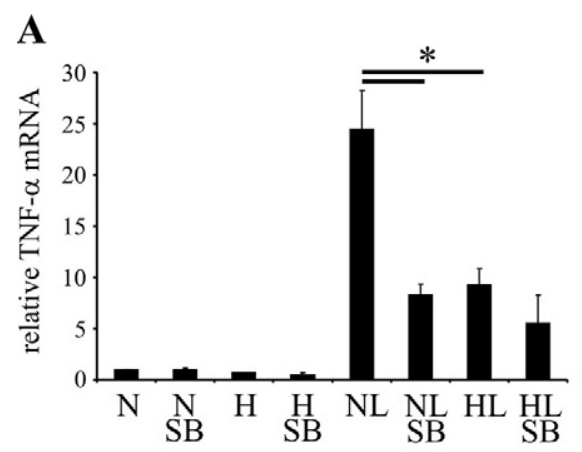

B

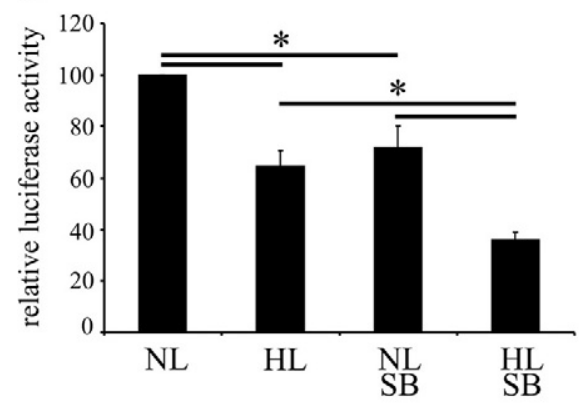

C

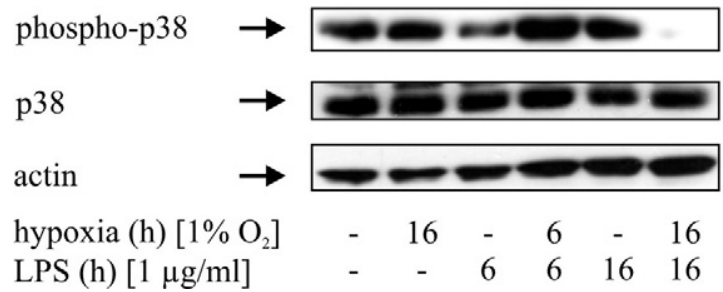

Figure 3. Phosphorylation of p38-MAPK affects destabilization of TNF- $\alpha$ mRNA. A: RAW264.7 cells were treated for 16 hours under normoxia $(\mathrm{N})$, hypoxia (H), normoxia/LPS ( $1 \mu \mathrm{g} / \mathrm{ml}$ ) (NL) or hypoxia/LPS (HL) with or without the p38-MAPK inhibitor SB203580 (SB) $(5 \mu \mathrm{mol} / \mathrm{L})$. SB203580 was preincubated for 30 minutes. TNF- $\alpha$ mRNA levels were normalized to ribosomal protein mRNA and calculated relative to normoxia levels as determined by quantitative real-time RT-PCR. B: RAW 264.7 cells were transfected with pMT2-luc-control and pMT2-luc-TNF-3'-UTR and stimulated for 16 hours with LPS under normoxia (NL) or hypoxia (HL) with or without SB203580. The ratio of pMT2-luc-TNF-3'UTR and PMT2-luc-control luciferase activity under normoxia/LPS was set to 100. Data are the means $\pm \operatorname{SEM}(n=\geq 3)$. Significant changes ${ }^{*} P<0.05$. C: RAW 264.7 cells were treated for 6 and 16 hours under normoxia or hypoxia with or without the addition of LPS $(1 \mu \mathrm{g} / \mathrm{ml})$. Expression of phospho-p38, total $\mathrm{p} 38$, and actin was followed by Western analysis. Results are representative for at least three independent experiments.
The inhibition of p38-MAPK under hypoxia/LPS $(5.5 \pm 2.8$ fold) provoked a slight additional decrease in TNF- $\alpha$ mRNA. Furthermore, inhibition of p38-MAPK under normoxia/LPS significantly decreased the 3'-UTR-mediated stability of the pMT2-luc-TNF-3'-UTR construct to values observed under hypoxia/LPS (Figure 3B). Additional inhibition of p38-MAPK under hypoxia/LPS further destabilized the pMT2-luc-TNF-3'-UTR construct. Because these data indicated a pivotal role of p38-MAPK in destabilizing TNF- $\alpha$ mRNA under prolonged hypoxic conditions, we next investigated phosphorylation of p38MAPK, as an indicator of its activity. Although the amount of phospho-p38 increased after 6 hours of hypoxia/LPS compared with normoxia/LPS treatments, p38-MAPK phosphorylation was almost completely abolished by 16-hour incubations under hypoxia/LPS. Incubations with LPS under normoxia for 16 hours resulted in p38-MAPK phosphorylation comparable to that of normoxic or hypoxic controls (Figure 3C). These data point to the importance of the p38-MAPK system for destabilizing TNF- $\alpha$ mRNA under prolonged hypoxia/LPS treatments.

\section{Hypoxia/LPS Increased TTP mRNA, Protein, and Activity}

Previously, TTP was shown to destabilize TNF- $\alpha$ mRNA by binding to ARE regions in its $3^{\prime}-\mathrm{UTR}^{9}{ }^{9}$ Because the p38-MAPK pathway was shown to be important for regulating TTP activity and stability, we investigated whether the protein amount or phosphorylation of TTP was changed under prolonged treatments with hypoxia/ LPS. As shown in Figure 4A the combination of hypoxia and LPS increased TTP protein levels compared with those for normoxia/LPS. Interestingly, the TTP protein accumulating under hypoxia/LPS migrated at a lower molecular weight compared with TTP accumulating under normoxia/LPS. Considering that the lower molecular weight might be a consequence of dephosphorylation, we determined the phosphorylation status of TTP by using an Ab raised against Ser178-phosphorylated TTP. TTP protein accumulating under normoxia/LPS was phosphorylated, whereas TTP accumulated in a dephosphorylated form under hypoxia/LPS (Figure 4A). To elucidate the mechanisms accounting for TTP accumulation, we determined changes in TTP mRNA levels and protein stability. TTP mRNA increased in response to LPS treatment under normoxia. Hypoxia/LPS led to a further, significant increase in TTP mRNA (Figure 4B). Because dephosphorylated TTP protein was reported to be rapidly degraded, we went on to determine protein stability of TTP accumulating under hypoxia/LPS. Inhibition of translation by cycloheximide $(5 \mu \mathrm{g} / \mathrm{ml})$ revealed that phosphorylated TTP under normoxia/LPS and dephosphorylated TTP under hypoxia/LPS were both stable to a similar degree (Figure 4C). Addition of SB203580 for the last hour of the 16-hour-long normoxia/LPS incubations before cycloheximide was supplied strongly reduced the stability of TTP protein, whereas inhibition of p38-MAPK had no effect on TTP protein stability under hypoxia/LPS. 
A

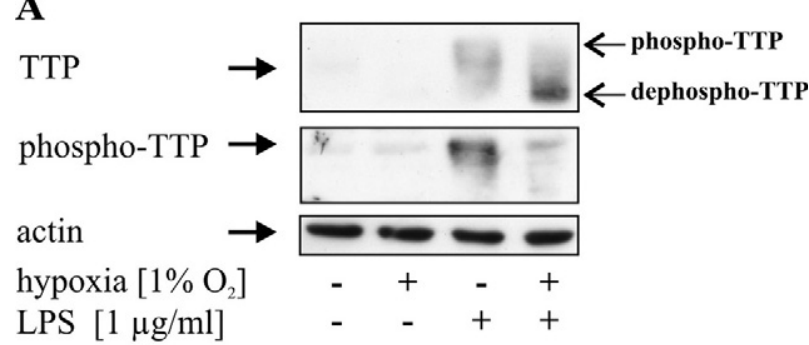

B

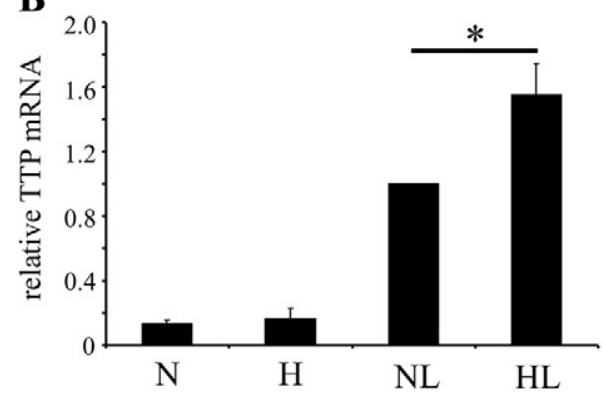

C

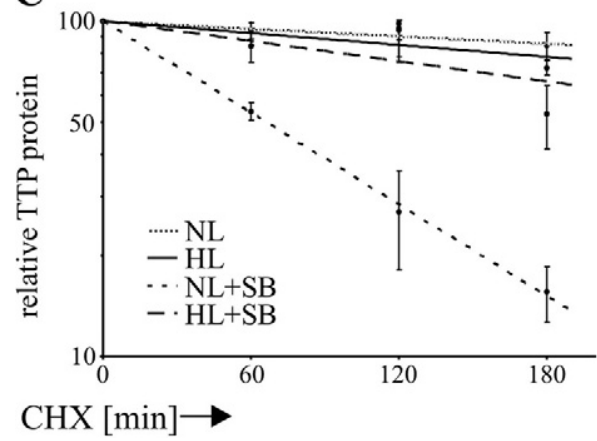

Figure 4. Hypoxia/LPS modulates TTP mRNA and protein stability. A: RAW264.7 cells were treated for 16 hours under normoxia or hypoxia with or without the addition of LPS $(1 \mu \mathrm{g} / \mathrm{ml})$. Expression of TTP, phospho-TTP and actin was followed by Western analysis. Results are representative of at least three independent experiments. B: RAW264.7 cells were treated for 16 hours under normoxia $(\mathrm{N})$, hypoxia $(\mathrm{H})$, normoxia/LPS $(\mathrm{NL})$, or hypoxia/LPS (HL). TTP mRNA levels were normalized to ribosomal protein mRNA and calculated relative to NL levels as determined by quantitative real-time RT-PCR. Data are the means $\pm \operatorname{SEM}(n=\geq 3)$. Significant changes ${ }^{*} P<0.05$. C: RAW264.7 cells were treated with LPS for 16 hours under normoxia (NL) or hypoxia (HL) with or without addition of $5 \mu \mathrm{mol} / \mathrm{L}$ SB203580 for the last hour $(\mathrm{NL}+\mathrm{SB}, \mathrm{HL}+\mathrm{SB})$. Protein translation was blocked by addition of cycloheximide (CHX) $(5 \mu \mathrm{g} / \mathrm{ml})$, and incubations were continued for up to 3 hours. Expression of TTP and actin were followed by Western analysis. Densitometric analysis was calculated from the ratios of TTP to actin by setting NL, HL, NL+SB, and HL + SB at 16 hours as 100. Data are the means $\pm \operatorname{SEM}(n=\geq 3)$.

These data indicate that prolonged treatments with hypoxia/LPS accumulated TTP mRNA and dephosphorylated TTP protein, without attenuating protein stability.

\section{TTP Mediated TNF- $\alpha$ mRNA Decay and}

\section{Reduced mRNA Expression of Proinflammatory} Mediators under Hypoxia/LPS

To provide further evidence for the role of TTP in regulating TNF- $\alpha$ mRNA stability under hypoxia/LPS, we used an siRNA approach to reduce TTP. The LPS-induced TTP mRNA increase was strongly attenuated by siRNA-mediated knockdown of TTP compared with cells transfected
A

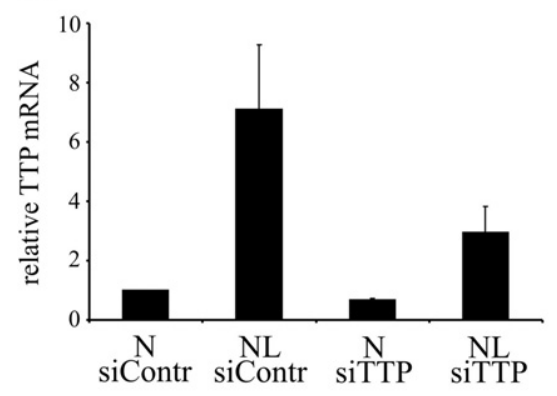

B

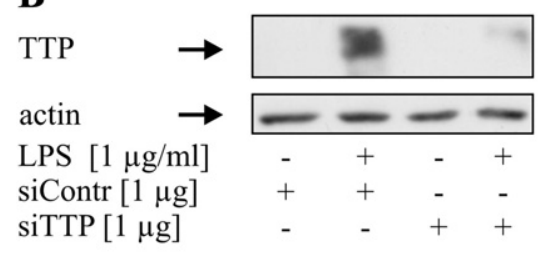

C

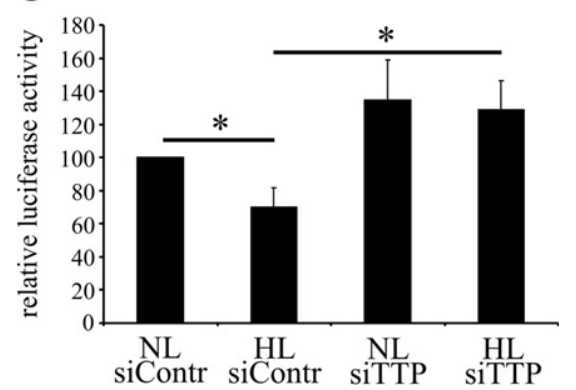

Figure 5. TTP destabilizes TNF- $\alpha$ mRNA under hypoxia/LPS. A: RAW294.7 cells were transfected with siControl $(1 \mu \mathrm{g})$ or siTTP $(1 \mu \mathrm{g}) 1$ day before experiments. After a 16-hour stimulation with LPS ( $1 \mu \mathrm{g} / \mathrm{ml})(\mathrm{NL})$, TTP mRNA levels were normalized to ribosomal protein mRNA and calculated relative to normoxia $(\mathrm{N})+$ siControl (siContr) levels as determined by quantitative real-time RT-PCR. B: Expression of TTP and actin were followed by Western analysis. Results are representative of at least three independent experiments C: RAW294.7 cells were transfected with siControl $(1 \mu \mathrm{g})$ or siTTP $(1 \mu \mathrm{g}) 1$ day before transfection with pMT2-luc-control and PMT2-luc-TNF-3'-UTR. After a 16-hour incubation with LPS under normoxia (NL) or hypoxia (HL), luciferase activity was measured. The ratio of pMT2-luc-TNF-3'-UTR to pMT2-luc-control luciferase activity under NL was set as 100. Data are the means $\pm \operatorname{SEM}(n=\geq 3)$. Significant changes ${ }^{*} P<0.05$.

with nontargeting siRNA (Figure 5A). In addition, the knockdown of TTP markedly reduced LPS-induced TTP protein accumulation (Figure 5B). Furthermore, silencing TTP significantly stabilized the pMT2-luc-TNF-3'-UTR reporter under hypoxia/LPS, producing relative luciferase values $(128.9 \pm 17.4 \%)$ that are comparable to levels seen under normoxia/LPS (134.6 $\pm 24.3 \%$ ) (Figure 5 C). In contrast, nontargeting siRNA-transfected cells displayed decreased PMT2-luc-TNF-3'-UTR reporter stability in response to hypoxia/LPS (70 $\pm 11.8 \%$ ) (Figure 5 C), similar to data obtained for endogenous TTP levels (Figure $2 \mathrm{C}$ ). These results support the notion that TNF- $\alpha$ mRNA destabilization by prolonged periods of exposure to hypoxia/LPS requires TTP. To assess whether our observations can be generalized, we analyzed the expression of additional proinflammatory mediators that were described as targets of TTP-dependent mRNA destabilization. Similar to the regulation of the TNF- $\alpha$ transcript (Figure 1A), mRNA expression of MIP-2, IL-6, and GM-CSF was not changed or even slightly induced during 
A
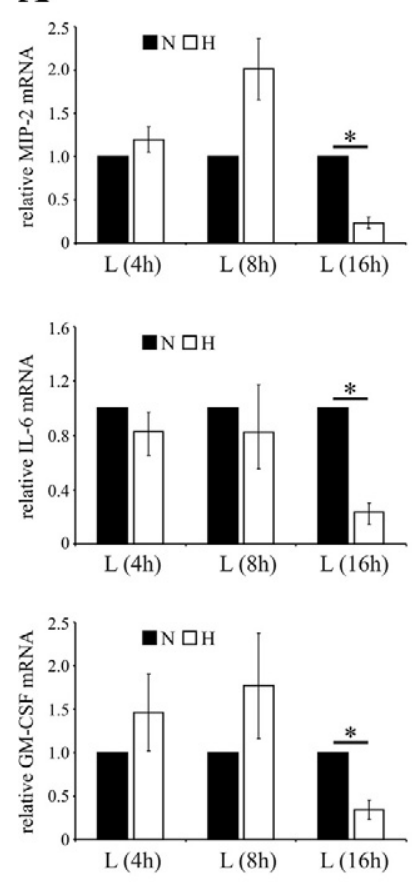

B
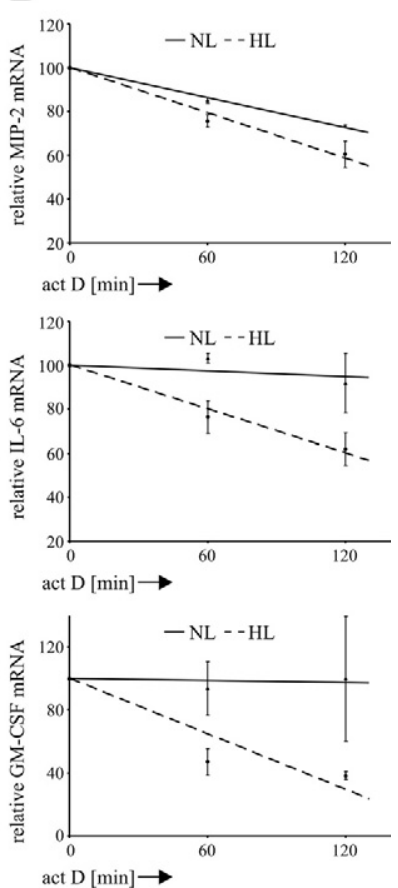

Figure 6. Hypoxia/LPS reduces mRNA levels and stability of MIP-2, IL-6, and GM-CSF. A: RAW264.7 cells were treated for the indicated times under normoxia (N, black bar) or hypoxia (H, white bar) with LPS ( $1 \mu \mathrm{g} / \mathrm{ml})(\mathrm{L})$. MIP-2, IL-6, and GM-CSF mRNA levels were normalized to ribosomal protein mRNA and calculated relative to appropriate normoxia/LPS levels as determined by quantitative real-time RT-PCR. B: RAW264.7 cells were exposed for 16 hours to normoxia/ LPS $(1 \mu \mathrm{g} / \mathrm{ml})$ (NL) or hypoxia/LPS (HL). Subsequently, transcription was blocked by adding actinomycin $\mathrm{D}(2.5 \mu \mathrm{g} / \mathrm{ml})$ for the times indicated. MIP-2, IL-6, GM-CSF, and ribosomal protein mRNA were determined by quantitative real-time RT-PCR. The ratios of MIP-2, IL- 6 , and GM-CSF to ribosomal protein mRNA after 16 hours of normoxia/LPS or hypoxia/LPS were set to 100. Data are the means $\pm \operatorname{SEM}(n=\geq 3)$. Significant changes ${ }^{*} P<0.05$.

8-hour incubations under hypoxia/LPS compared with normoxia/LPS (Figure 6A). However, prolonged exposure of macrophages for 16 hours to hypoxia/LPS, significantly reduced MIP-2, IL-6, and GM-CSF mRNA amounts compared with normoxia/LPS (Figure 6A). To further investigate whether mRNA reduction resulted from mRNA destabilization, we treated macrophages for 16 hours under normoxia/ LPS or hypoxia/LPS before blocking transcription by adding actinomycin D $(2.5 \mu \mathrm{g} / \mathrm{ml})$ for another 120 minutes. Incubations under hypoxia/LPS decreased the stability of MIP-2, IL-6, and GM-CSF mRNAs compared with normoxia/LPS (Figure 6B).

Taking these results together, we propose that prolonged hypoxia contributes to the resolution of LPS-induced inflammation by decreasing the mRNA stability of proinflammatory mediators such as TNF- $\alpha$, MIP-2, IL-6, and GM-CSF. An important mediator of this effect is the mRNA-destabilizing protein TTP.

\section{Discussion}

Hypoxia is a characteristic feature of the tissue environment during bacterial infections. ${ }^{23}$ We provide evidence that prolonged periods of hypoxia terminate LPS-dependent expression of proinflammatory mediators. Specifically, TNF- $\alpha$

mRNA stability is reduced because the mRNA-destabilizing ARE-binding protein TTP is activated. Increased TTP activity is caused by accumulation of active TTP protein due to inactivation of its negative regulator p38-MAPK in response to long-term hypoxia/LPS treatments.

$\mathrm{TNF}-\alpha$ production is regulated by changes in gene transcription, mRNA stability, processing of the precursor protein, and secretion of the bioactive protein. ${ }^{24}$ Despite this knowledge, TNF- $\alpha$ regulation under hypoxic conditions remains a matter of ongoing discussion. In contrast with reports showing that macrophages exposed to hypoxia/LPS produce high levels of TNF- $\alpha$, which was attributed to transcriptional activation of the TNF- $\alpha$ promoter by nuclear factor- $\kappa \mathrm{B}$ and/or hypoxia-inducible factor $-1,{ }^{2-4}$ we and others have seen that short-term incubations (for up to 8 hours) of macrophages under hypoxia/LPS provoked no further TNF- $\alpha$ mRNA increase compared with normoxia/LPS. ${ }^{5,7}$ However, we provide evidence that long-term exposure for 16 hours to hypoxia/LPS decreased TNF- $\alpha$ mRNA, diminished the amount of the precursor protein, and consequently reduced the capacity of macrophages to secrete TNF- $\alpha$ protein. These observations corroborate work by Lahat et al, ${ }^{8}$ who showed that severe hypoxia $\left(\mathrm{O}_{2}<0.3 \%\right)$ in combination with LPS, supplied for 24 hours under serum-starved conditions, reduced intracellular and secreted TNF- $\alpha$ protein levels. Enhanced lysosomal degradation of $\mathrm{TNF}-\alpha$ protein was put forward as the underlying mechanism. Interestingly, the authors noticed only a fivefold TNF- $\alpha$ mRNA increase after 24-hour incubations with LPS under both normoxia and hypoxia. In contrast, our data provide evidence that macrophages still express high levels of TNF- $\alpha$ mRNA (24.4 \pm 3.79-fold) after a 16-hour exposure to normoxia/ LPS, whereas these levels are strongly down-regulated under hypoxic incubations (9.2 \pm 1.62 -fold), which also has been reconfirmed in primary macrophages. Despite differences in the severity of hypoxia in our study versus the study of Lahat et al, we suggest that TNF- $\alpha$ mRNA induction by LPS is transient, and, thus, TNF- $\alpha$ mRNA levels are already reduced after 24 hours under normoxic conditions, whereas hypoxia accelerates the termination of TNF- $\alpha$ production via destabilization of the mRNA. The possibility that the remaining intracellular TNF- $\alpha$ precursor might be removed by lysosomal degradation cannot be ruled out.

Several RNA-binding proteins such as $\mathrm{Hu}$ antigen $\mathrm{R}$ and polypyrimidine tract-binding protein have been implicated in facilitating the cellular response to hypoxia. They seem to enhance the expression of hypoxia-response proteins such as hypoxia-inducible factor-1 and vascular endothelial growth factor. ${ }^{25}$ However, the influence of hypoxia on TTP-dependent gene regulation has not yet been investigated. We show that mRNA, protein expression, and activity of TTP is increased after 16 hours of hypoxia/LPS. TTP strongly attenuates inflammatory processes as demonstrated by the inflammatory phenotype of TTP knockout mice. ${ }^{9}$ The importance of the TTPTNF- $\alpha$ axis for the regulation of inflammatory conditions was further corroborated by Kontoyiannis et al, ${ }^{26}$ who showed that transgenic mice lacking the ARE sequences in TNF- $\alpha$ transcripts displayed pathological overexpres- 
sion of TNF- $\alpha$, resulting in an inflammatory phenotype. Although many reports focused on TTP inactivation (eg, by LPS) as a mechanism of stabilizing proinflammatory mRNAs, only a few reports revealed physiological stimuli activating TTP. Recently, the anti-inflammatory mediators IL-10 and adiponectin were shown to activate TTP. 27,28 In both studies, activation of TTP strongly decreased TNF- $\alpha$ levels in response to LPS treatment in macrophages. Mechanistically, TTP activation in response to IL-10 or adiponectin resulted from decreased phosphorylation of TTP by P38-MAPK. We noticed decreased p38-MAPK activity when LPS was supplied under long-term hypoxia, which caused accumulation of dephosphorylated and active TTP. In contrast, short-term hypoxia is known to increase p38-MAPK phosphorylation, ${ }^{29-31}$ indicating that a direct exposure of macrophages to hypoxia may even trigger inflammatory responses. This is also reflected by our observations that LPS-provoked phospho-p38 was enhanced after 6 hours of hypoxia compared with normoxia and the finding that GM-CSF and MIP-2 mRNA were increased after 8-hour incubations of hypoxia/LPS. Although short-time incubations did not reduce and even increased TNF- $\alpha$, IL-6, MIP-2, and GM-CSF mRNA expression, long-term incubations with hypoxia/LPS attenuated phosphorylation of p38-MAPK. Consequently, TTP got activated and destabilized target mRNAs. p38-MAPK was previously shown to stimulate mitogen-activated protein kinase-activated protein kinase-2, which provokes phosphorylation of TTP at serines 52 and 178 to facilitate formation of TTP-14-3-3 complexes. Binding of 14-3-3 chaperones to TTP inhibits both TTP activity and protein degradation. ${ }^{18,19}$ Dephosphorylation results in reactivation of TTP, destabilization of target mRNAs, and degradation of TTP protein. ${ }^{15}$ In contrast, our data suggest stabilization of dephosphorylated, ie, active TTP protein in response to prolonged periods of hypoxia/LPS. Further investigations are required to elucidate the underlying mechanism of stabilizing dephosphorylated TTP.

Based on reports indicating that TTP destabilizes the mRNA of a wide number of proinflammatory mediators ${ }^{32}$ and on our observation that reactivation of TTP by hypoxia/LPS is accompanied by down-regulation and destabilization of TNF- $\alpha$, IL-6, MIP-2, and GM-CSF mRNAs, we propose a key role of TTP during resolution of inflammation. Furthermore, we suggest that hypoxic conditions, which are characteristic for tissue environments during bacterial infections ${ }^{1}$ initiate these processes.

In summary, we provide evidence for stabilization of dephosphorylated TTP by prolonged hypoxia/LPS treatments as a new aspect of TTP activity regulation. We conclude that this mechanism is essential for destabilization of proinflammatory mRNAs and propose that TTP activation in hypoxic environments is a key regulatory mechanism for resolution of inflammation.

\section{Acknowledgments}

We thank Dr. Andrew R. Clark (London, UK) for providing antiserum against TTP and Dr. Georg Stoecklin (Heidelberg, Germany) for providing the anti-phospho-TTP Ab and the luciferase reporter plasmids pMT2-Iuc-control and PMT2-luc-TNF-3'-UTR.

\section{References}

1. Lewis JS, Lee JA, Underwood JC, Harris AL, Lewis CE: Macrophage responses to hypoxia: relevance to disease mechanisms. J Leukoc Biol 1999, 66:889-900

2. Chandel NS, Schumacker PT, Arch RH: Reactive oxygen species are downstream products of TRAF-mediated signal transduction. J Biol Chem 2001, 276:42728-42736

3. Cramer T, Yamanishi Y, Clausen BE, Forster I, Pawlinski R, Mackman N, Haase VH, Jaenisch R, Corr M, Nizet V, Firestein GS, Gerber HP Ferrara N, Johnson RS: HIF- $1 \alpha$ is essential for myeloid cell-mediated inflammation. Cell 2003, 112:645-657

4. Leeper-Woodford SK, Detmer K: Acute hypoxia increases alveolar macrophage tumor necrosis factor activity and alters NF- $\kappa$ B expression. Am J Physiol 1999, 276:L909-L916

5. Ndengele MM, Bellone CJ, Lechner AJ, Matuschak GM: Brief hypoxia differentially regulates LPS-induced IL-1 $\beta$ and TNF- $\alpha$ gene transcription in RAW 264.7 cells. Am J Physiol Lung Cell Mol Physiol 2000 , 278:L1289-L1296

6. Kim HY, Kim YH, Nam BH, Kong HJ, Kim HH, Kim YJ, An WG, Cheong $\mathrm{J}$ : HIF-1 $\alpha$ expression in response to lipopolysaccaride mediates induction of hepatic inflammatory cytokine TNF $\alpha$. Exp Cell Res 2007, 313:1866-1876

7. Liu FQ, Liu Y, Lui VC, Lamb JR, Tam PK, Chen Y: Hypoxia modulates lipopolysaccharide induced TNF- $\alpha$ expression in murine macrophages. Exp Cell Res 2008, 314:1327-1336

8. Lahat N, Rahat MA, Kinarty A, Weiss-Cerem L, Pinchevski S, Bitterman $\mathrm{H}$ : Hypoxia enhances lysosomal TNF- $\alpha$ degradation in mouse peritoneal macrophages. Am J Physiol Cell Physiol 2008, 295:C2-C12

9. Carballo E, Lai WS, Blackshear PJ: Feedback inhibition of macrophage tumor necrosis factor- $\alpha$ production by tristetraprolin. Science 1998, 281:1001-1005

10. Carballo E, Lai WS, Blackshear PJ: Evidence that tristetraprolin is a physiological regulator of granulocyte-macrophage colony-stimulating factor messenger RNA deadenylation and stability. Blood 2000, 95:1891-1899

11. Jalonen U, Nieminen R, Vuolteenaho K, Kankaanranta $H$, Moilanen E: Down-regulation of tristetraprolin expression results in enhanced IL-12 and MIP-2 production and reduced MIP-3 $\alpha$ synthesis in activated macrophages. Mediators Inflamm 2006, 2006:40691

12. Ogilvie RL, Abelson M, Hau HH, Vlasova I, Blackshear PJ, Bohjanen PR: Tristetraprolin down-regulates IL-2 gene expression through AUrich element-mediated mRNA decay. J Immunol 2005, 174:953-961

13. Ogilvie RL, Sternjohn JR, Rattenbacher B, Vlasova IA, Williams DA, $\mathrm{Hau} \mathrm{HH}$, Blackshear PJ, Bohjanen PR: Tristetraprolin mediates interferon- $\gamma$ mRNA decay. J Biol Chem 2009, 284:11216-11223

14. Stoecklin G, Stoeckle P, Lu M, Muehlemann O, Moroni C: Cellular mutants define a common mRNA degradation pathway targeting cytokine AU-rich elements. RNA 2001, 7:1578-1588

15. Brook M, Tchen CR, Santalucia T, Mcllrath J, Arthur JS, Saklatvala J, Clark AR: Posttranslational regulation of tristetraprolin subcellular localization and protein stability by p38 mitogen-activated protein kinase and extracellular signal-regulated kinase pathways. Mol Cell Biol 2006, 26:2408-2418

16. Hitti E, lakovleva T, Brook M, Deppenmeier S, Gruber AD, Radzioch D, Clark AR, Blackshear PJ, Kotlyarov A, Gaestel M: Mitogen-activated protein kinase-activated protein kinase 2 regulates tumor necrosis factor mRNA stability and translation mainly by altering tristetraprolin expression, stability, and binding to adenine/uridine-rich element. Mol Cell Biol 2006, 26:2399-2407

17. Carballo E, Cao H, Lai WS, Kennington EA, Campbell D, Blackshear PJ: Decreased sensitivity of tristetraprolin-deficient cells to p38 inhibitors suggests the involvement of tristetraprolin in the p38 signaling pathway. J Biol Chem 2001, 276:42580-42587

18. Stoecklin G, Stubbs T, Kedersha N, Wax S, Rigby WF, Blackwell TK Anderson P: MK2-induced tristetraprolin:14-3-3 complexes prevent stress granule association and ARE-mRNA decay. EMBO J 2004, 23:1313-1324 
19. Chrestensen CA, Schroeder MJ, Shabanowitz J, Hunt DF, Pelo JW, Worthington MT, Sturgill TW: MAPKAP kinase 2 phosphorylates tristetraprolin on in vivo sites including Ser178, a site required for 14-3-3 binding. J Biol Chem 2004, 279:10176-10184

20. Mahtani KR, Brook M, Dean JL, Sully G, Saklatvala J, Clark AR: Mitogen-activated protein kinase p38 controls the expression and posttranslational modification of tristetraprolin, a regulator of tumor necrosis factor $\alpha$ mRNA stability. Mol Cell Biol 2001, 21:6461-6469

21. Sun L, Stoecklin G, Van Way S, Hinkovska-Galcheva V, Guo RF, Anderson P, Shanley TP: Tristetraprolin (TTP)-14-3-3 complex formation protects TTP from dephosphorylation by protein phosphatase $2 a$ and stabilizes tumor necrosis factor- $\alpha$ mRNA. J Biol Chem 2007, 282:3766-3777

22. Dean JL, Sully G, Clark AR, Saklatvala J: The involvement of AU-rich element-binding proteins in p38 mitogen-activated protein kinase pathway-mediated mRNA stabilisation. Cell Signal 2004, 16:1113-1121

23. Peyssonaux C, Johnson RS: An unexpected role for hypoxic response: oxygenation and inflammation. Cell Cycle 2004, 3:168-171

24. Papadakis KA, Targan SR: Tumor necrosis factor: biology and therapeutic inhibitors. Gastroenterology 2000, 119:1148-1157

25. Masuda K, Abdelmohsen K, Gorospe M: RNA-binding proteins implicated in the hypoxic response, J Cell Mol Med 2009, 13:2759-2769

26. Kontoyiannis D, Pasparakis M, Pizarro TT, Cominelli F, Kollias G: Impaired on/off regulation of TNF biosynthesis in mice lacking TNF
AU-rich elements: implications for joint and gut-associated immunopathologies. Immunity 1999, 10:387-398

27. Park PH, Huang H, McMullen MR, Mandal P, Sun L, Nagy LE: Suppression of lipopolysaccharide-stimulated tumor necrosis factor- $\alpha$ production by adiponectin is mediated by transcriptional and posttranscriptional mechanisms. J Biol Chem 2008, 283:26850-26858

28. Schaljo B, Kratochvill F, Gratz N, Sadzak I, Sauer I, Hammer M, Vogl C, Strobl B, Muller M, Blackshear PJ, Poli V, Lang R, Murray PJ, Kovarik $P$ : Tristetraprolin is required for full anti-inflammatory response of murine macrophages to IL-10. J Immunol 2009 183:1197-1206

29. Conrad PW, Rust RT, Han J, Millhorn DE, Beitner-Johnson D Selective activation of $\mathrm{p} 38 \alpha$ and $\mathrm{p} 38 \gamma$ by hypoxia. Role in regulation of cyclin D1 by hypoxia in PC12 cells, J Biol Chem 1999, 274:23570-23576

30. Kulisz A, Chen N, Chandel NS, Shao Z, Schumacker PT: Mitochondrial ROS initiate phosphorylation of p38 MAP kinase during hypoxia in cardiomyocytes. Am J Physiol Lung Cell Mol Physiol 2002, 282:L1324-L1329

31. Xu L, Pathak PS, Fukumura D: Hypoxia-induced activation of p38 mitogen-activated protein kinase and phosphatidylinositol 3'-kinase signaling pathways contributes to expression of interleukin 8 in human ovarian carcinoma cells. Clin Cancer Res 2004, 10:701-707

32. Sandler H, Stoecklin G: Control of mRNA decay by phosphorylation of tristetraprolin. Biochem Soc Trans 2008, 36:491-496 